\title{
Erratum to: Molecular Modeling of Ammonium, Calcium, Sulfur, and Sodium Lignosulphonates in Acid and Basic Aqueous Environments
}

P. J. Salazar Valencia ${ }^{1}$ - L. E. Bolívar Marinez ${ }^{1}$.

S. T. Pérez Merchancano ${ }^{1}$

Published online: 23 September 2015

(C) Sociedade Brasileira de Física 2015

Erratum to: Brazilian Journal of Physics

DOI 10.1007/s13538-015-0364-5

L. E. Bolívar Marinez's family name is corrected as shown in this erratum.

$\triangle$ P. J. Salazar Valencia

pjsalazar@unicauca.edu.co

1 Universidad del Cauca, Calle 5 Núm. 4-70, Campus Tulcan,

Popayán, Colombia 